\title{
Influence of Ion Nitriding Process on the Properties of Zirconia Coating Deposited on Stainless Steel
}

\author{
B. J. Gómez, ${ }^{*}$ R. Caruso, ${ }^{* \dagger}$ L. Nachez, ${ }^{*}$ A. Díaz-Parralejo, ${ }^{\ddagger}$ J. Feugeas, ${ }^{*}$ and O. de Sanctis*† \\ *IFIR,(CONICET-UNR) Bv. 27 de Febrero 210 bis S2000EZP Rosario, Argentina \\ ${ }^{\dagger}$ Lab. Mat. Ceram. UNR Pellegrini 250, 2000 Rosario, Argentina \\ *Universidad de Extremadura, 06071 Badajoz, España
}

Received on 8 December, 2005

\begin{abstract}
$\mathrm{ZrO}_{2}-3$ mol $\% \mathrm{Y}_{2} \mathrm{O}_{3}$-coated AISI 310 stainless steel was nitrided using plasma produced by dc pulsed discharge in a mixture of $\mathrm{N}_{2}$ and $\mathrm{H}_{2}$ at an equilibrium temperature of $450^{\circ} \mathrm{C}$. Profile chemical analyses with GDOS (glow discharge optical spectroscopy) and XRD showed the formation of Nitrogen/Y- $\mathrm{ZrO}_{2}$ solid solution. Nitrogen atoms enter in the zirconia substituting to the oxygen atoms in the network. Although, the nitrogen content measured in zirconia coating is greater than the allowed maximum nitrogen content in doped-zirconia solid solution, the formation of oxynitrides could not be detected. The phase structure was investigated by Xray diffractometry The mechanical properties were studied by means ultramicrohardness indentation tests. The nitruration improves the mechanical responses of the $\mathrm{ZrO}_{2}-3 \mathrm{~mol} \% \mathrm{Y}_{2} \mathrm{O}_{3}$-coated AISI 310 stainless steel.
\end{abstract}

Keywords: Ion nitriding; Zirconia coatings; Nitrurated coatings

\section{INTRODUCTION}

Nitrided metals have excellent mechanical properties such as high hardness and wearing resistance. On the other hand, yttria-stabilized zirconias (YSZ), in addition to having good mechanical properties, such as high hardness and fracture toughness, exhibit outstanding thermal stability and corrosion-resistant properties [1]. Consequently, yttriastabilized zirconia is widely used as protection coating for metallic surfaces where thermal and corrosion resistance are required [2].

Nitrogen-containing zirconia solid solution and zirconium oxynitrides (e.g., $\gamma-\mathrm{Zr}_{2} \mathrm{ON}_{2}$ ) have attracted attention due to their improved mechanical and thermal properties as compared with those obtained for oxide based systems [3, 4]. Several processes can be used to nitriding zirconia such as solidstate reactions [5] or reaction in vapor phase [6]. Most of them are generally based on treatments to high temperatures. The ion-nitriding process has been widely used to nitride metallic surfaces, normal steels and stainless steels at relatively low temperature $[7,8]$. The aim of the present work is to use the ion-nitriding process in nitriding yttria-stabilized zirconia films deposited on AISI 310 stainless steels. The composition, crystalline structural and mechanical properties of the prepared samples will be analyzed.

\section{EXPERIMENTAL DETAILS}

\section{A. Yttria-doped zirconia coating preparation}

The starting solution was prepared by stirring zirconium n-propoxide (ZNP) (70 wt\% in 2-propanol Alfa 22989), 1propanol and $\mathrm{HNO}_{3}$ as catalyst agents in an anhydrous $\mathrm{N}$ atmosphere to avoid hydroxide precipitation. After $6 \mathrm{~h}$, distilled water was carefully added, followed by stirring during $24 \mathrm{~h}$ until a quite transparent solution was obtained. The $\mathrm{ZNP} / \mathrm{H}_{2} \mathrm{O} / \mathrm{HNO}_{3}$ molar ratios achieved the $1 / 7 / 1$ values and the $\mathrm{ZrO}_{2}$ concentration in the solution was $77 \mathrm{~g} / \mathrm{l}$. The final sol-gel solution was obtained by adding in the $\mathrm{Zr}$ solution Yttrium acetate $(99.9 \%)$ dissolved in $\mathrm{PrOH}$ and $\mathrm{HNO}_{3}$. This step was performed under stirring in normal atmosphere. The resulting $\mathrm{ZNP} / \mathrm{PrOH} / \mathrm{H}_{2} \mathrm{O} / \mathrm{HNO}_{3}$ molar ratio was $1 / 15 / 5 / 1$, and the nominal concentration of yttria in oxide was 2.5 mol\%. The AISI 310 stainless steel substrate (supplied by Goodfellow Ltd.) were polished ( $1 \mu m$ diamond paste) and cleaned in ethanol. In order to enhance the adhesion of the zirconia films, the metallic substrate was oxidized by heat treatment at $300{ }^{\circ} \mathrm{C}$ in air for $1 \mathrm{~h}$ before depositing the films by the dip-coating method [9]. The dipping was made with a withdrawal rate of $14 \mathrm{~cm} / \mathrm{min}$. A 10 layer coating of about $2 \mu \mathrm{m}$ was produced by a multilayer deposition process [10]. After each deposition, the film was dried and after heated at $800{ }^{\circ} \mathrm{C}$ for $2 \mathrm{~h}$ in normal atmosphere.

\section{B. Plasma reactor and nitriding conditions}

The plasma is generated as quiescent discharge (glow discharge) inside the reactor chamber, between the cathode (samples holder) and the grounded anode (chamber walls) [11]. The gas composition was $70 \% \mathrm{~N}_{2}$ mixed with $30 \% \mathrm{H}_{2}$ maintained inside the chamber at a constant pressure of $533.3 \mathrm{~Pa}$ and at $450{ }^{\circ} \mathrm{C}$ (equilibrium temperature) for $5 \mathrm{~h}$. In this work, the applied voltage, frequency and the active to passive ratio was $500 \mathrm{~V}, 100 \mathrm{~Hz}$ and $80 \%$ to $20 \%$, respectively.

\section{Coating characterization}

The XRD pattern was obtained using a Philips PW-1800 powder diffractometer with $C u K_{\alpha}$ radiation $(\lambda=1.54183 \AA)$. The diffraction data were collected over a $2 \theta$ range of $25-90^{\circ}$ with a step width $0.02^{\circ}$ of and a counting time of $5 \mathrm{~s} / \mathrm{step}$. Depth profiling element analyses were obtained using a Leco glow discharge-optical emission spectrometer (Grimm-type lamp, 4- $m m$ anode diameter) applying a electric discharge onto the sample surface at controlled voltage, current, and Ar 
atmosphere [10].

Sputter rates were roughly calibrated using $\mathrm{ZrO}_{2}$ multilayer coatings prepared by the authors with thickness and porosity pre-determined $[10,12]$. Coating thickness is estimated by assuming that the metallic/ ceramic interface is located where the Iron $(\mathrm{Fe})$ content is 50the bulk substrate value.

Ultramicrohardness tests were performed to study the mechanical response of the samples. The values of ultramicrohardness $(H)$ and the Young's modulus $(E)$ were obtained, from the indentation load-unload curves [13], [14]. The tests were performed at loads of $20 \mathrm{mN}$ by using a Berkovich indenter (three-sided pyramid).

In order to overcome measurement errors due to imperfections in the indenter tip, Indentation Size Effect corrections [10], $H$ and $E$ values were measured by conventional tests on AISI 310 and reference materials (bulk Mg-partially stabilized zirconia, and sapphire) and compared with the values obtained by ultramicrohardness tests.

The $H$ was measured with Vickers indenter (Shimadzu Micro Hardness Tester Type M) using a load of $200 \mathrm{~g}$. Hertzian contact tests [15] were used to determine the elastic modulus of bulk materials (AISI 310 substrate, bulk Mg-PSZ and sapphire), using a mechanical testing machine with load-depth data acquisition software (Instron 5565, Instron Corp., Canton, MA).

\section{RESULTS AND DISCUSSION}

\section{A. Depth profiling quantitative analysis}

Fig. 1 shows the elemental depth profile obtained in the coating deposited on the AISI 310 (Sample $C$ ). The $[\mathrm{Zr}] /[\mathrm{O}]$ ratio maintains almost constant equal to 0.5 throughout the coating. $[\mathrm{Zr}]$ steeply decreases in the zone where $[\mathrm{Fe}]$ increases, which is located around a depth of $2 \mu \mathrm{m}$, and it forms an intermediate region between zirconia coating and metallic substrate of about $300 \mathrm{~nm}$.

The depth profiling analysis of nitrided coating (Sample NC) shows (Fig.2) that the $[N]$ is very high near the surface $(\approx 0.9)$, and steeply, it decreases to a value of $\approx 0.4$ at a depth with depth of $0.250 \mu \mathrm{m}$, deeper the $[N]$ decreasing lightly until near the interface. On the interface, $[N]$ falls fast until being almost negligible in the metallic substrate. Tacking into account the result in the ion nitrided steel substrate where the $N$ diffuse far away from the surface (estimated roughly in 100 $\mu m$ ), the almost negligible $[N]$ in the metallic substrate for nitriding zirconia-AISI 310 would act as a barrier that inhibits the $N$ diffusion. Also from a chemical composition point of view, the $[N]$ (an average concentration of 0.3 ) in the zirconia coating (Fig.2) is an unexpected result, because it is grater than the maximun $[N]$ in solid solution as well as than the $[N]$ as oxynitrides.

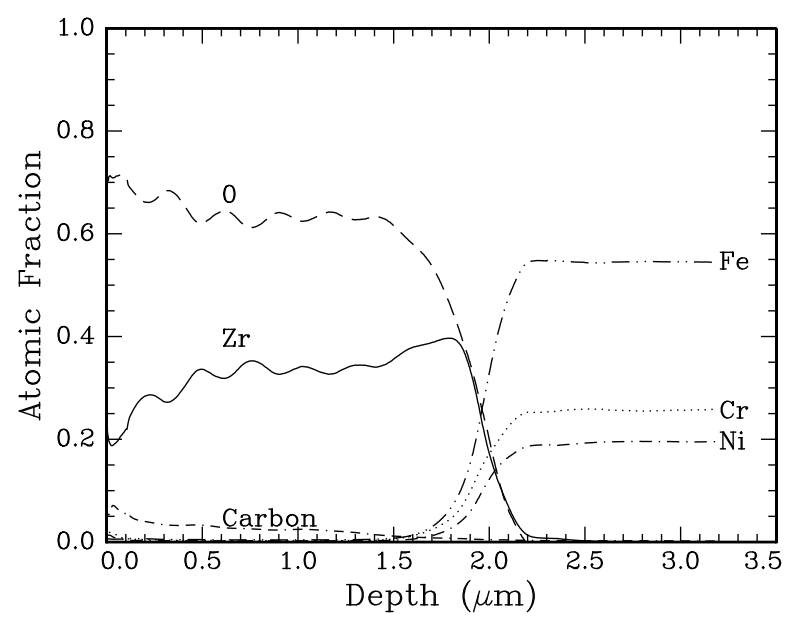

FIG. 1: Depth profiling quantitative analysis results corresponding to coating on AISI 310 stainless steel substrate (Sample $C$ ).

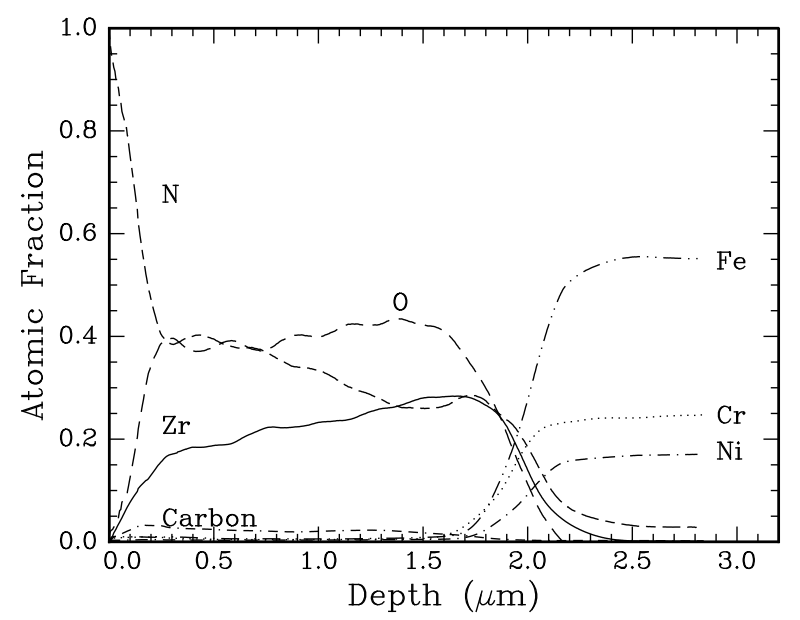

FIG. 2: Depth profiling quantitative analysis results corresponding to coating on AISI 310 stainless steel substrate after the ion nitriding process (Sample NC).

\section{B. Structural and microstructural characterization}

Fig. 3 shows the XRD pattern of sample $C$ and $N C$. The XRD spectrum of the $N C$ exhibits a change only a high angle peaks shifting with respect to the spectrum of the $C$, which indicates a decrease in the lattice parameter. The smaller lattice parameter would indicate than $N$ atom enter in the zirconia substituting the $O$ atoms in the network. This result has been previously reported in bulk samples for Nitrogencontaining $8 \mathrm{Y} / \mathrm{ZrO}_{2}$ fully cubic stabilized zirconia [16]. In order to maintain network neutrality, the introduction of the $N$ into zirconia results in $O$ vacancies in the anion sub-lattice as required $\mathrm{N}^{3-}$ substitution for $\mathrm{O}^{2-}$ anions. Therefore, the $O$ vacancies in the $3 Y / \mathrm{ZrO}_{2}$ films are in fact a combination 
of the vacancies introduced by both $Y^{3+}\left(Y^{3+}\right.$ substituted for $\mathrm{Zr}^{4+}$ in the cation sub- lattice) and $N^{3-}\left(N^{3-}\right.$ substituted for $\mathrm{O}^{2-}$ in the anion sub-lattice) giving a formula:

$$
Z r_{0.94} Y_{0.06} O_{1.97-1.5 x} N_{x} V_{O_{0.029+x / 2}}
$$

Taking into account the results obtained by Cheng and Thompson [16] that the $[N]$ cubic Zirconia becomes unstable when the overall $O$ vacancies are beyond $\approx 6 \%\left(\left[V_{O}{ }^{*}\right] /[Z r]\right.$ $=0.12)$, resulting $x_{\max }=0.18$ and consequently $[N]_{\max } /[\mathrm{Zr}]$ $\approx 0.2$. The $[\mathrm{N}] /[\mathrm{Zr}]$ ratio in the ion nitrided $3 \mathrm{Y} / \mathrm{ZrO}_{2}$ films is five times that maximum $[N]_{\max } /[\mathrm{Zr}]$. Therefore, it was expected the formation of Zirconium nitride and/or Zirconium oxynitrides. However, the Zirconium nitride peaks are not observed and could not be asserted undoubtedly the presence of the room temperature stable Zirconium oxynitride $\left(\gamma-\mathrm{Zr}_{2} \mathrm{ON}_{2}\right)$ because their peaks are severely overlapped with those of the zirconia cubic phase. Taking into account the low temperature of ion nitriding process, it is possible to hypothesize the presence of $N_{2}$ trapped inside either the central octahedral interstices of zirconia structure or in the residual pores of the coating.

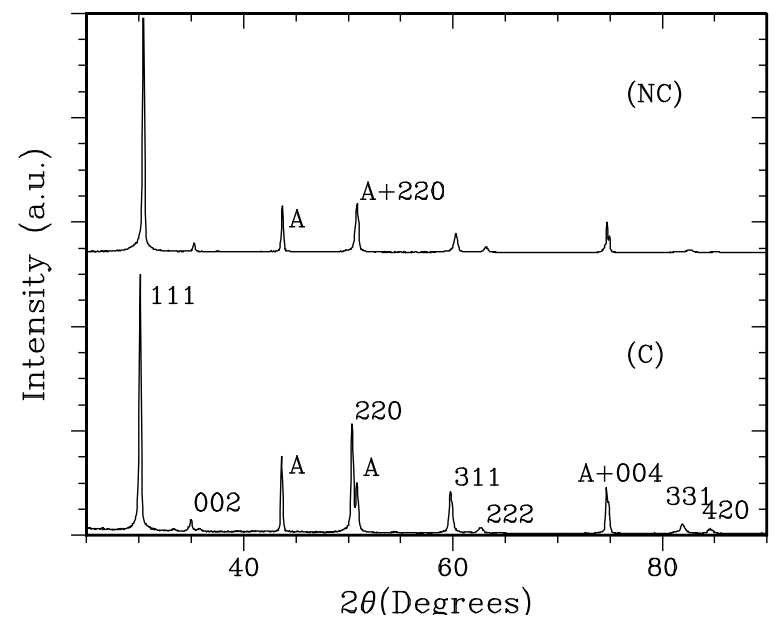

FIG. 3: XRD patterns of sample $C$ and $N C$. Crystallographic reflections are shown for peaks corresponding to the zirconia coating; peaks noted as $A$ correspond to the austenitic substrate phase.

\section{Mechanical properties}

Figure 4 shows the experimental Berkovich loadpenetration depth curves corresponding to the bared AISI 310 substrate $(S)$, sample $C$ and bulk Mg-PSZ sample ( $Z$ ). This latter sample has been incorporated as reference material. In order to analyze the intrinsic mechanical response of coating the penetration depth of the Berkovich indenter was less than $1 / 7$ of the coating thickness. The curve of sample $C$ shows typical behaviour of a ceramic material characterized by a major elastic recovery during unloading (about $60 \%$ ) and a

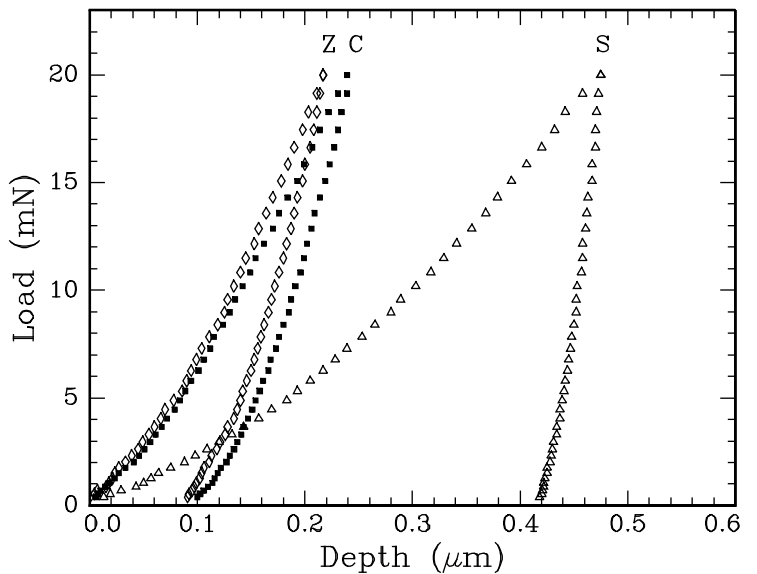

FIG. 4: Experimental Berkovich load-penetration depth curves $(P=$ $20 \mathrm{mN}$ ) corresponding to AISI 310 substrate $(S)$, sample $C$ and bulk Mg-PSZ sample ( $Z$ ).

penetration depth at $20 \mathrm{mN}$ load that is about a half of the one corresponding to the metallic surface. Fig.5 shows the experimental load-penetration depth curves corresponding to the sample $N C$. As references, the figure also includes the indentation curve of sample $C$ and to the bulk sapphire sample $(S A)$.

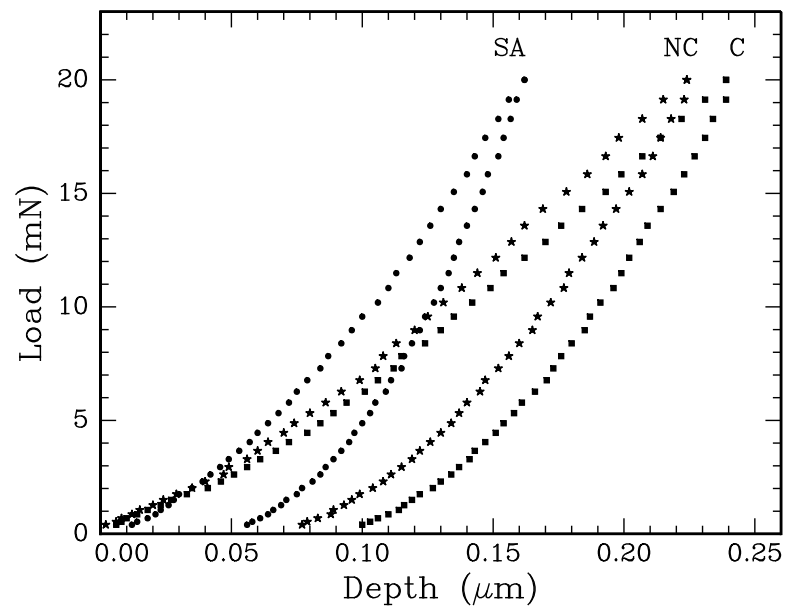

FIG. 5: Experimental Berkovich load-penetration depth curves ( $P$ $=20 \mathrm{mN}$ ) corresponding to sample $C$, and $N C$ and bulk sapphire sample $(S A)$.

Using the method described in a previous work [10], we have obtained the $H^{*}$ and $E^{*}$ of the samples. The results are shown in Table I with an error estimated of about $5 \%$.

The ion nitriding process had increased the mechanical response of the coating, as can be seen from the higher $H^{*}$ and $E^{*}$ values of the $N C$ respect to the observed for $C$. In order to be sure that the values obtained by Berkovich ultramicrohardness tests are not distorted by errors inherent to measurement 
TABLE I: Mechanical responses. (Berkovich test and conventional test (with $200 \mathrm{~g}$ load))

\begin{tabular}{|l|lc|lc|}
\hline Sample & Berkovich & \multicolumn{2}{|l|}{ Conventional } \\
\hline & $E^{*}(G P a)$ & $H^{*}(G P a)$ & $E(G P a)$ & $H(G P a)$ \\
\hline S & $200 \pm 10$ & $2.0 \pm 0.1$ & $200 \pm 10$ & $2.0 \pm 0.1$ \\
C & $190 \pm 10$ & $10.0 \pm 0.5$ & & \\
NC & $210 \pm 10$ & $13.0 \pm 0.7$ & & \\
SA & $370 \pm 20$ & $20 \pm 1$ & $380 \pm 20$ & $20 \pm 1$ \\
Z & $220 \pm 10$ & $12.0 \pm 0.6$ & $210 \pm 10$ & $12.0 \pm 0.6$ \\
\hline
\end{tabular}

method [10], conventional tests were performed on the bulk materials (Table I). The values obtained by both method are very similar as well as to the data found in the literature for those materials [17, 18].

\section{CONCLUSIONS AND IMPLICATIONS}

$\mathrm{ZrO}_{2}-3 \mathrm{~mol} \% \mathrm{Y}_{2} \mathrm{O}_{3}$ on AISI 310 stainless steel has been nitrided using an ion-nitriding process at $450^{\circ}$, in $\mathrm{N}_{2} / \mathrm{H}_{2}$ plasma.We have found that the ion-nitriding process allows the incorporation of higher $[N]$ into the zirconia coating at lower temperatures than with the corresponding one to conventional processes. Although the highest $[N]$ observed in the most superficial layer of the zirconia coating, the $N$ diffuses along the whole of the layer of the zirconia until the zirconiasteel interface. However, the $N$ locates mainly in the zirconia film and almost vanishes in the stainless steel substrate. This behaviour can be explained looking the zirconia coating as a trap for the $N$, screening the diffused $N$ toward the stainless steel substrate. $O$ substitution by $N$ entering the zirconia layer is suggested as the trapping mechanism. The introduction of $\mathrm{N}$ into $\mathrm{ZrO}_{2}-3$ mol\% $\mathrm{Y}_{2} \mathrm{O}_{3}$ creates additional $O$ vacancies in the anion sublattice as required by charge neutrality for $N^{3-}$ replacing $O^{2-}$ in the structure. On the other hand, as the formation of oxynitrides compounds have not been undoubtedly observed, the excess of the $N$ can be attributed to the presence of $N_{2}$ inside the zirconia coatings. Finally, we have shown that the ion nitriding process improves the mechanical responses of the $\mathrm{ZrO}_{2}-3 \mathrm{~mol} \% \mathrm{Y}_{2} \mathrm{O}_{3}$-coated AISI 310 stainless steel.

\section{Acknowledgments}

A grateful acknowledgment to Conicet (Argentina) and the Agencia Nacional de Promoción Científica y Tecnológica, Argentina,
[1] M. Atik, M. A. Aegerter, J. Non-Cryst. Solids, 147-148, 813 (1992).

[2] H. Makishima, M. Oohashi, K. Wakakuwa, K. Kotani, and T. Shimohira, J. Non-Cryst. Solids 42, 545 (1980).

[3] A. D. Mazzoni, E. F. Aglietti, Mater. Chem. Phys.65, 166 (2000).

[4] S. Komarneni, J. Mater. Chem. 2, 1219 (1992).

[5] T. J. Chung, J. S. Lee, D. Y. Kim, and H. Song, J Am. Ceram. Soc. 84 (1), 172 (2001).

[6] M. Lerch, J. Am. Ceram. Soc. 79 (10), 2641 (1996).

[7] T. Bell Surf. Eng. 6 (1), 31 (1990).

[8] A. Leyland, K. S. Fancey, and A. Matthews, Surf. Eng. 7, 31 (1991).

[9] O. de Sanctis, L. Gómez, N. Pellegri, and A. Duran, Surf. Coat. Technol., 70, 251 (1995).

[10] R. Caruso, A. Díaz Parralejo, F. Guiberteau, and P. Miranda, Journal of Material Research, 16 (8), 2391 (2001).

[11] J. Feugeas, B. J. Gómez, and A. Craievich, Surf. Coat. Technol.
154, 167 (2002).

[12] A. Díaz Parralejo, R. Caruso, A.L. Ortiz, and F. Guiberteau, Thin Solid Films 458, 92 (2004).

[13] J. L. Loubet J. M. Georges, and G. Meille Microindentation Techniques in materials Science and Engineering, STP vol 889 American Society for Testing Materials West Conshohocken, PA 1989, 72.

[14] L. Riester, M. K. Ferber, Plastic Deformation of Ceramics Plenum Press NY 1995.

[15] F. Guiberteau, N. P. Padture, H. Cai, and B. R. Lawn, Philos. Mag. A 68, 1003 (1993).

[16] Y. B. Cheng, D. P. Thompson, J. Am. Ceram. Soc. 76 (3), 683 (1993).

[17] I. J. McColm, Ceramic Hardness Plenum Press NY 1990.

[18] J. B. Wachtman, Mechanical Properties of Ceramics, John Wiley \& Sons, Inc., NY 1996. 